\title{
Correction to: Technology adoption to reduce the harvesting losses and wastes in agriculture
}

\author{
Debesh Mishra ${ }^{1} \cdot$ Suchismita Satapathy ${ }^{1}$ (I)
}

Published online: 24 May 2021

๑) Springer-Verlag GmbH Germany, part of Springer Nature 2021

\section{Correction to: Clean Technologies and Environmental Policy https://doi.org/10.1007/s10098-021-02075-2}

In the original publication, the information under the section Independent-factors (Cluster-IV) was published incorrectly. The correct information is provided below:

\section{Independent-factors (Cluster-IV)}

Similar to cluster-II, none of the factors of technology adoption was found under this category.

Publisher's Note Springer Nature remains neutral with regard to jurisdictional claims in published maps and institutional affiliations.

The original article can be found online at https://doi.org/10.1007/ s10098-021-02075-2.

Suchismita Satapathy

suchismitasatapathy9@gmail.com

1 SME, KIIT deemed to be University, Bhubaneswar 751024,

Odisha, India 